\title{
Reviewer Acknowledgments 2017
}

The Editor-in-Chief of the International Journal of Latin American Religions would like to thank all of our reviewers, both external and Editorial Board Members, who have contributed to the journal in Volume 1 (2017) and whose valuable support is fundamental to the success of the journal. The expertise and contribution of the reviewers are critical to continually maintain the good standard of our publication.

\author{
Ana Maria Bidegain \\ Bettina Schmidt \\ Cristina Gutiérrez Zuñiga \\ Cristina Pátaro \\ Edin Sued Abumanssur \\ Eduardo Cruz \\ Emerson Giumbelli \\ Ênio José da Costa Brito \\ Fatima Regina Machado \\ Fernando Londoño \\ Harold Morales \\ Henri Gooren \\ Jakob Thorsen \\ John Thomas Huber II \\ Leonildo Silveira Campos
}

\author{
Luis Rodolfo Moran Quiroz \\ Maia Guillot \\ Manéli Farahmand \\ Marcelo Camurça \\ María Eugenia Patiño \\ Marina Correa \\ Nahayeilli Juarez Huet \\ Óscar Figueroa Castro \\ Rafael Shoji \\ Renato Graziano Battistella \\ Roberta Ricucci \\ Sergio Botta \\ Steven Engler \\ Timothy J. Steigenga \\ Willis Guerra
}

